\title{
http://dx.doi.org/10.5664/jcsm.2026 \\ PFO and Right-to-Left Shunting in Patients with Obstructive Sleep Apnea
}

\author{
Marina Guchlerner, M.D. '; Peter Kardos, M.D.2; Eva Liss-Koch, M.D. 2; Jennifer Franke, M.D. '; Nina Wunderlich, M.D.'; \\ Stefan Bertog, M.D. ${ }^{1} ;$ Horst Sievert, M.D. ${ }^{1}$ \\ ${ }^{1}$ CardioVascular Center Frankfurt, Sankt Katharinen, Frankfurt, Germany; ${ }^{2}$ Gemeinschaftspraxis und Zentrum für \\ Pneumologie, Allergologie \& Schlafmedizin, Klinik Maingau, Frankfurt, Germany
}

Background: Patent foramen ovale (PFO) with right-to-left shunt has a prevalence of $10 \%$ to $34 \%$ in the general population. It can cause an ischemic stroke, transient ischemic attack, and paradoxical peripheral or coronary embolization. Its influence on migraine and several other diseases and conditions is currently under debate. Attention has recently been turned to the correlation between PFO and obstructive sleep apnea. Thus far, studies on the prevalence of right-to-left shunts as a surrogate for PFO in these patients were limited by small sample sizes and the results have been conflicting. Here, we evaluate the prevalence of right-to-left shunting (RLS) through transcranial Doppler ultrasound (TCD) in a large patient group with obstructive sleep apnea (OSA).

Methods: One hundred consecutive patients (mean age $59.5 \mathrm{y}$ ) with OSA underwent TCD with intravenous injection of agitated saline. The grading of right-to-left-shunts was in ac- cordance with the Spencer PFO Grading Scale.

Results: RLS was detected in 72 of 100 patients (72\%). Thirtyfour out of these 72 patients (47\%) had a shunt grade I or II; 15 (21\%) had a shunt Grade III or IV; and $23(32 \%)$ had a large shunt (Grade $V$ or $V+$ ). In 47 of 72 patients (65\%), a right-to-left shunt was detectable at rest without Valsalva maneuver.

Conclusion: The prevalence of a RLS in patients with OSA is high. Provided other intracardiac or pulmonary shunts were absent, the high prevalence of a RLS suggests a high prevalence of PFO in patients with OSA.

Keywords: Obstructive sleep apnea, patent foramen ovale, right-to-left-shunt, transcranial doppler

Citation: Guchlerner M; Kardos P; Liss-Koch E; Franke J; Wunderlich N; Bertog S; Sievert H. PFO and right-to-left shunting in patients with obstructive sleep apnea. J Clin Sleep Med 2012;8(4):375-380. p patent foramen ovale (PFO) can be detected in autopsy studies in $15 \%$ to $34 \%$ in the general population. ${ }^{1-3}$ It is reported in $26 \%$ of a randomly selected population cohort examined by transesophageal echocardiography (TEE) ${ }^{4}$ A higher prevalence has been reported in patients suffering from migraine or cluster headache, ${ }^{5,6}$ as well as in subjects with ischemic stroke. ${ }^{7}$ Case reports of thrombi-in-transit and a plausible physiologic mechanism support the notion that PFO are a potential cause for paradoxical peripheral and coronary embolization $^{8}$ and decompression sickness. ${ }^{9}$

Transesophageal echocardiography using contrast (agitated saline injection) has been demonstrated to have a high sensitivity and specificity for the detection of a PFO causing a rightto-left shunt when compared with autopsy studies ${ }^{3}$ and has, therefore, been considered the gold standard diagnostic test for the detection of a PFO. However, recent studies have shown contrast-enhanced TCD and TEE to be complementary techniques in the assessment of a PFO. ${ }^{10}$

In fact, some evidence suggests that TCD may be more sensitive in the detection of RLS than echocardiographic imaging. ${ }^{11}$ Therefore, this technique may be able to exclude PFO causing RLS with a higher level of confidence than TEE and transthoracic echocardiography..$^{12}$ Assuming no other (unusual) intracardiac or intrapulmonary shunts are present, a RLS detected on TCD is indicative of a PFO. Furthermore, TCD is considerably less invasive for the patient, and the Valsalva maneuver,

\section{BRIEF SUMMARY}

Current Knowledge/Study Rationale: Right-to-left shunting (RLS) via a patent foramen ovale (PFO) may exacerbate hypoxemia caused by apneic episodes. In addition, apneic episodes may promote rightto-left shunting through a foramen ovale. To date, it has not yet been determined whether obstructive sleep apnea (OSA) is associated with a higher prevalence of RLS through a patent foramen ovale.

Study Impact: Our findings may impact the management of patients with OSA. It should stimulate further investigations to determine if patients with severe OSA and RLS through a PFO should undergo PFO closure.

which significantly increases microbubble appearance,,$^{13}$ can be performed more accurately. Further investigations demonstrated that the unilateral detection of RLS by power M-mode transcranial Doppler, used in this study, provided an equivalent sensitivity to a bilateral detection, ${ }^{14}$ while easier to handle. Recognizing the limitation that, in unusual circumstances, a RLS detected on TCD may be the source of other intracardiac or intrapulmonary shunts and that a PFO may remain silent if it causes left-to-right shunting only, the presence of RLS demonstrated by TCD will, for the remainder of this discussion and manuscript, be assumed to be the consequence of PFO with RLS. Moreover, the term "PFO" will indicate PFO with RLS unless otherwise stated. 
Obstructive sleep apnea (OSA) is a common condition affecting $17 \%$ to $26 \%$ of men and $9 \%$ to $28 \%$ of women over 30 years of age with a higher prevalence in both the elderly and the overweight. ${ }^{15-17}$ Several disorders are associated with this condition: systemic and pulmonary hypertension, ischemic heart disease, cardiac arrhythmia, cerebrovascular disease, congestive heart failure, ${ }^{18-20}$ as well as cognitive dysfunction $^{21}$ and an increased risk of accidents as a result of daytime sleepiness. ${ }^{22}$

Improvements in the degree of hypoxemia in patients with both OSA and PFO after closure of the PFO are conceivable. Data, to support this, however are limited to case reports. For example, subjective improvement in sleep apnea symptoms and objective improvement in polysomnographic testing after transcutaneous closure of a PFO in a patient after ischemic stroke have been reported. ${ }^{23}$ Moreover, complete resolution of symptoms in a patient with OSA and desaturations during exercise has been described. ${ }^{24}$

It is not yet clear whether OSA, by virtue of increased mean transmural pulmonary artery pressure during apneic episodes,,$^{25}$ may allow an interatrial communication (PFO) that otherwise would be unrecognized, whether the PFO is a substantial contributor in the pathogenesis of OSA, or whether both apply.

Recent research indicates that carbon dioxide retention and hypoxemia during nocturnal apneic episodes in patients with obstructive sleep apnea (OSA) lead to an elevation of pulmonary vascular resistance followed by an increase in right ventricular afterload and right atrial pressure. Under these conditions, right-to-left shunting via PFO may exacerbate the hypoxemia caused by apneic episodes. ${ }^{26}$

Importantly, it has not yet been determined whether OSA is associated with an increased prevalence of PFO. Previous studies examining the prevalence of PFO in patients with OSA have produced conflicting results. ${ }^{27,28}$

The aim of this study was to evaluate the prevalence of rightto-left shunting by means of TCD in a large group of patients with obstructive sleep apnea syndrome. Care was taken to include a nonselected cohort of consecutive patients representative of a general OSA population.

\section{PATIENTS AND METHODS}

\section{Study Sample}

One hundred consecutive patients first time diagnosed with OSA after clinical assessment and inpatient overnight sleep studies requiring nocturnal positive airway pressure treatment were screened for PFO.

\section{Polysomnography}

The diagnosis of OSA was made after performing a standard nocturnal polysomnography including electroencephalogram, electroculograms, single-lead electrocardiogram, anterior tibial and submental electromyograms, finger pulse oximetry, and measurements of oro-nasal-airflow as well as abdominal and chest excursions.

A single expert evaluated the polysomnograms manually. Respiratory events were counted as apnea if a cessation of airflow $\geq 10 \mathrm{sec}$ occurred. Hypopnea was defined as $\geq 50 \%$ reduc- tion of airflow, in association with an oxygen desaturation $\geq 4 \%$ from the baseline value, lasting $>10$ seconds.

Continuous oxygen saturation $\left(\mathrm{SaO}_{2}\right)$ measurement allowed determination of the number of desaturations $>4 \%$ per hour sleep time (oxygen desaturation index, ODI). The frequency of apneas and hypopneas per hour of sleep (apnea hypopnea index, AHI) defined the OSA severity. AHI $>5$ was considered pathological.

\section{Shunt Detection and Assessment}

To evaluate the presence of PFO, a transcranial Doppler was performed in every patient. We used the ST3 Digital Transcranial Doppler System Model PMD 150 (Spencer Technologies, Seattle, WA, USA), with Power M-Mode and injection of contrast medium, to discover RLS. The machine provides 33 gates of continuous Doppler information across a $66 \mathrm{~mm}$ depth range. There are 2 sections on display:

1. Digital Power M-Mode (mm): This shows all blood flow within a depth range. Blue represents blood flow away from the transducer, red towards the transducer. Brighter color corresponds to stronger signals. Blood flow signals cause a horizontal streak across the screen when located.

2. Spectrogram $(\mathrm{cm} / \mathrm{s})$ : shows a Doppler spectral waveform that indicates the velocity profile of blood flow in the selected depth.

All examination data were stored internally and analyzed offline afterwards by a single experienced researcher.

Patients were placed in supine position with their head slightly elevated. An intravenous catheter (20-gauge) was inserted into the antecubital vein. The transcranial $2 \mathrm{MHz}$ ultrasound probe was fixed unilaterally on the patients' head, at the height of the temporal bone window, by using the Marc 600 Headframe System (Spencer Technologies, Seattle, WA). The Doppler signal of blood flow in the middle cerebral artery was located at a depth of $45-65 \mathrm{~mm}$. At this point, the Valsalva maneuver was exercised with the patient: the patient was asked to take a deep breath and press against the closed epiglottis for $10 \mathrm{sec}$ to increase the thoracic pressure. The maneuver was considered successful if a $30 \%$ reduction of mean flow velocity in the middle cerebral artery could be observed for the entire 10 -sec period. Before recording, two $10-\mathrm{mL}$ syringes were connected to the intravenous catheter by means of a 3-way stopcock: one containing $9 \mathrm{~mL}$ of 3.5\% colloidal solution Haemaccel (TheraSelect, Marburg, Germany) and $1 \mathrm{~mL}$ of air, the other empty. The content was agitated by rapidly pushing it from one syringe to the other, resulting in a homogenous solution (the contrast agent).

In the following examination, 2 sessions were performed: in the first session the contrast bolus was rapidly injected (within 6-8 $\mathrm{sec}$ ) with the patient at rest during physiological respiration. In the second session, the patient was asked to perform the Valsalva maneuver as previously practiced. Midway through the injection, the patient was instructed to start the Valsalva maneuver and hold it for $10 \mathrm{sec}$ before breathing normally again. There was a 5-min break between the sessions to allow the recirculating bubbles to disperse. Embolic tracks were counted for a total of $60 \mathrm{sec}$ after the end of each injection.

Microembolic signals can be distinguished from artifacts (caused by patient movement, swallowing, chewing, or manipulation of the probe) in the spectrogram by their characteristic 
Figure1A_ST3 Digital Transcranial Doppler System Model PMD 150; divided display: power M-Mode (upper part), spectrogram (lower part); One microembolic signal (MES)

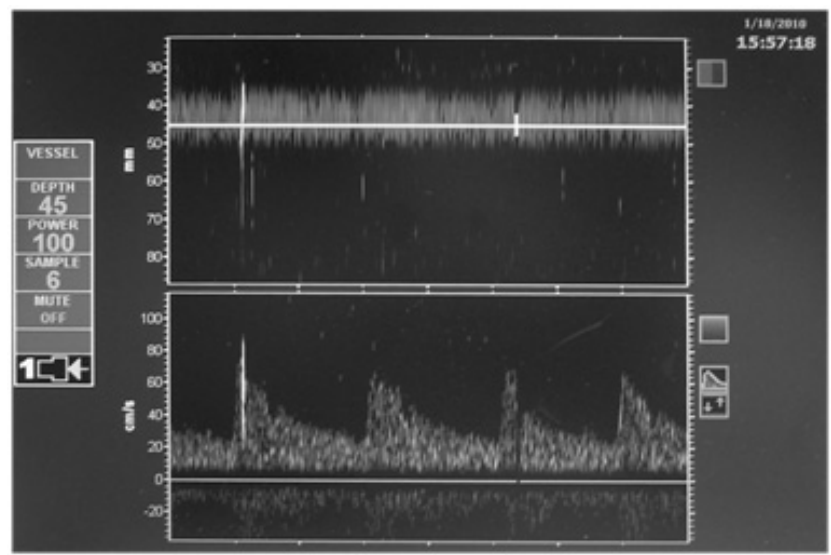

Table 1-Spencer Grading Scale; MES: microembolic signals

$\begin{array}{ll}\text { Grade I } & 1-5 \text { MES } \\ \text { Grade II } & 6-15 \text { MES } \\ \text { Grade III } & 16-50 \text { MES } \\ \text { Grade IV } & 51-150 \text { MES } \\ \text { Grade V } & >150 \text { MES } \\ \text { Grade V+ } & \text { "curtain" or "shower effect": uncountable number of MES }\end{array}$

sound and look. It is a short click-sound $(<300 \mathrm{~ms})$ of high intensity, visible as a white streak within the Doppler flow spectrum (Figure 1A and $\mathbf{B}$ ).

The magnitude of right-to-left shunting was classified according to the Spencer grading Scale (Spencer Vascular Laboratories, Seattle, Washington, USA; Table 1 $)^{29}$ A right-to-left shunt was noted to be present if $\geq 1$ clear microembolic signal had been recorded within $60 \mathrm{sec}$ after the end of the injection. At-rest shunting was noted if the patient showed a shunt during the first session (at physiological respiration). Provocative-only shunting was defined as microembolic signals (MES) recorded only during Valsalva maneuver and not under resting conditions.

\section{Statistical Analysis}

Statistical calculations were performed using the software "BiAS for Windows" version 9.07 (epsilon-Verlag, Darmstadt, Germany). Descriptive statistics were performed for demographic and polysomnographic characteristics (Table 2).

We evaluated the prevalence of PFO as well as the magnitudes of the right-to-left shunt in the study sample. The distribution of provocative-only shunting was compared to at-rest shunting.

The Mann-Whitney-Wilcoxon Test was used to compare continuous variables in the groups "no shunt" to "shunt" and, within the "shunt" group, to compare "at-rest shunting" to "provocative-only shunting." The clinical parameters considered were age, height, weight, body mass index, AHI, ODI, AHI/ ODI, baseline $\mathrm{SaO}_{2}$ during sleep, and lowest $\mathrm{SaO}_{2}$ during sleep.
Figure1B-Curtain pattern: uncountable MES; Shunt grade $\mathrm{V}+$

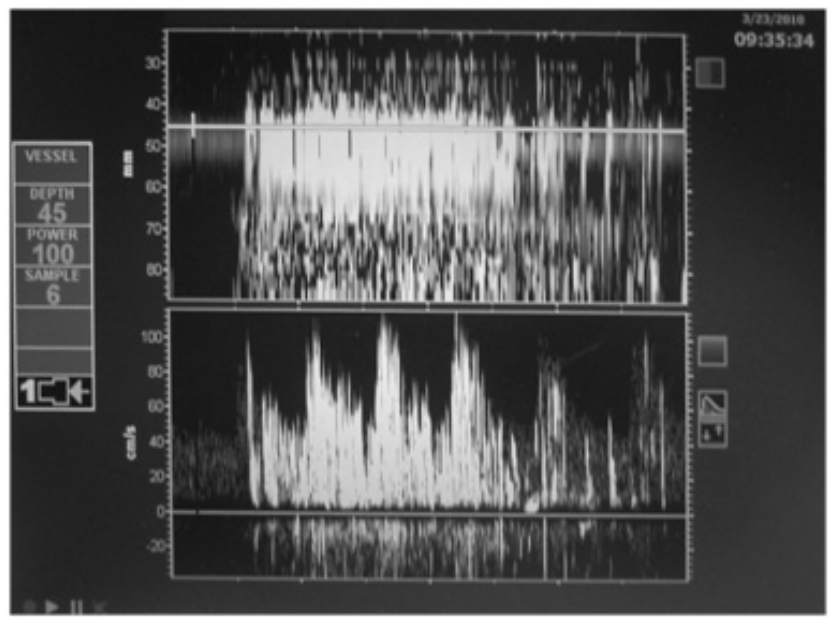

Table 2-Studied clinical parameters (mean \pm SD)

$\begin{array}{ll}\text { Gender (female; male, of } 100 \text { patients) } & 19 ; 81 \\ \text { Age (years) } & 59.5 \pm 11.7 \\ \mathrm{BMI}\left(\mathrm{kg} / \mathrm{m}^{2}\right) & 33.2 \pm 6.4 \\ \mathrm{AHI}(/ \mathrm{h}) & 44.2 \pm 20.2 \\ \mathrm{ODI}(/ \mathrm{h}) & 39.1 \pm 20.1 \\ \mathrm{AHI} / \mathrm{ODI} & 0.9 \pm 0.35 \\ \text { Baseline } \mathrm{SaO}_{2}(\%) & 91.6 \pm 3.7 \\ \text { Lowest } \mathrm{SaO}_{2}(\%) & 71.7 \pm 10.9\end{array}$

The Fisher exact test was used to compare categorical variables in the groups "no shunt" and "shunt." Gender and preexisting illnesses (hypertension, diabetes, coronary artery disease, atrial fibrillation, COPD/asthma, stroke; Table 3) were included in the analysis (Table 4). Spearman rank correlation was calculated to test for a statistically significant association between shunt magnitude and clinical parameters. A $p$ value $<0.05$ was considered statistically significant.

\section{RESULTS}

There were 19 females and 81 males in the study population. The mean age was $59.5 \pm 11.7$ years, mean BMI $33.2 \pm 6.4 \mathrm{~kg} /$ $\mathrm{m}^{2}$ and mean AHI $44.2 \pm 22.2 / \mathrm{h}$ (Table 2).

In 72 of $100(72 \%)$ patients, a right-to-left shunt was detected. Forty-seven of 72 patients (65\%) showed "at-rest shunting"- a right-to-left shunt during physiological respiration. A "provocative-only shunt"-a right-to-left shunt only after Valsalva maneuver - was present in 25 patients.

Out of these 72 patients, $34(47 \%)$ had a small shunt $(<15$ MES, conforming to grade I or II in the Spencer grading Scale); 38 patients $(53 \%)$ had a large shunt (grade III to $\mathrm{V}+$ ); and in 18 patients a curtain pattern was seen in $\mathrm{TCD}(\mathrm{V}+)$.

There was no significant correlation with the following parameters: gender, BMI, AHI, ODI, AHI/ODI, nadir oxygen saturation, lowest oxygen saturation, or concomitant diseases, and the presence or absence of a shunt either at rest or with Val- 


$\begin{array}{ll}\text { Table 3-Concomitant diseases in study population } \\ \text { Disease } & \text { No. of patients } \\ \text { Hypertension } & 61 \\ \text { Diabetes } & 18 \\ \text { Coronary artery disease } & 15 \\ \text { Atrial fibrillation } & 10 \\ \text { COPD/asthma } & 9 \\ \text { Stroke } & 6\end{array}$

salva. In addition, there was no significant correlation between the shunt magnitude and any of the aforementioned parameters.

\section{DISCUSSION}

The study reveals right-to-left shunting in $72 \%$ of patients with OSA. Provided no other sources (i.e., an intrapulmonary or other intracardiac RLS) are present, the etiology of the RLS in these patients is PFO. This is approximately three times higher than the reported prevalence of PFO in the general population at autopsy. It is also significantly higher than the prevalence reported by TEE in a large randomly selected population cohort $(26 \%) .{ }^{4}$ Of note, in the overwhelming majority in that cohort the PFO was diagnosed based on the presence of a RLS by contrast (agitated saline) injection. Our results confirm findings by Shoundy et al. ${ }^{27}$ The prevalence of PFO was $69 \%$ in patients with OSA analyzed by TEE (48 patients). In contrast, in a TCDstudy (78 patients), Beelke et al. report a prevalence of only $27 \%$, which lies within the range expected in the general population. ${ }^{28}$ However, this study only evaluated a selected group of patients with OSA. Patients with myocardial infarction, unstable angina, congestive heart failure, pulmonary embolism, transient ischemic attack, stroke, or migraine - all conditions frequently found in patients with $\mathrm{OSA}^{30}$-were excluded. Thus the study population may not have be representative of the general OSA patient population. Transcranial Doppler data regarding the prevalence of a RLS in a healthy population are limited and it could be argued that TCD is more sensitive or overestimates the true prevalence of RLS. However, though perhaps slightly more sensitive than TEE, ${ }^{10}$ the differences in reported prevalences between both modalities are small.

It has been hypothesized, that the high prevalence of PFO with RLS in OSA patients could be due to enhanced respiratory effort during apneic episodes causing a rise in right atrial pressure, allowing reopening of a patent but formerly closed foramen ${ }^{26}$; however, increased right atrial pressures in patients with isolated OSA have not yet been demonstrated. Likewise, increased right-sided pressure related to pulmonary hypertension may facilitate interatrial communication via the foramen ovale. Though it is controversial whether OSA alone (in the absence of concomitant pulmonary disease or daytime hypoxemia) can cause pulmonary hypertension, some recent data in patients whose sleep apnea was treated with continuous positive airway pressure causing a significant reduction in pulmonary artery pressure in the absence of changes in daytime hypoxemia or lung function tests does support the notion that OSA can lead to an increase (albeit mild) in pulmonary artery pressure. ${ }^{31}$ Finally,
Table 4-Relation between concomitant diseases and rightto-left shunt/shunt magnitude

\begin{tabular}{llc} 
Concomitant disease & \multicolumn{2}{c}{ p-value } \\
Hypertension & 0.3 & 0.3 \\
Diabetes & 0.1 & 0.19 \\
Coronary artery disease & 0.06 & 0.7 \\
Atrial fibrillation & 0.36 & 0.1 \\
COPD/asthma & 0.52 & 0.3 \\
Stroke & 0.2 & 0.11
\end{tabular}

both mechanisms in concert may permit a patent foramen ovale to re-establish. To this effect, high pulmonary artery systolic pressure is often measured in patients with $\mathrm{OSA}^{32}$ and attributed to pulmonary vasoconstriction caused by hypoxemia. ${ }^{33}$ Though the prevalence of PFO in patients with pulmonary hypertension is reported to be similar to the general population, ${ }^{34}$ a study of patients with chronic obstructive pulmonary disease (COPD) shows a significantly higher pulmonary artery systolic pressure and an increased prevalence for PFO assessed by transesophageal (agitated saline-) contrast echocardiography (70\%). ${ }^{35}$ Moreover, these patients experience significant systemic arterial oxygen desaturation after the Valsalva maneuver.

Similar observations have been made in OSA patients with PFO: these patients experience more oxygen desaturations in proportion to respiratory events (episodes of hypopnea and apnea) than patients without PFO. There appears to be a higher prevalence of PFO in patients with deep desaturations than in those with milder degrees $(60 \%$ vs. $13 \%) .{ }^{36}$ The right-to-left shunt occurring during obstructive respiratory disturbances (i.e., patients pressing against closed upper airway) allows deoxygenated venous blood to enter the arterial system and thereby may decrease arterial oxygen saturation.

There is a high correlation between MES count in TCD and PFO size. ${ }^{37}$ Thus one may assume that a larger shunt in TCD is related to a larger defect. The role of PFO and shunt size in the severity of desaturation is still not fully understood. In the current study, a significant correlation between shunt size and AHI (which indicates severity of OSA) could not be found.

There was no significant associated between any of the evaluated clinical parameters to the presence a shunt or its magnitude. This corresponds with previous study results. ${ }^{27,28}$

Case reports suggest an association between OSA and PFO. For example, in support of the hypothesis that PFO may exacerbate hypoxemia and unfavorably affect physiologic sleep parameters, significant improvements of OSA symptoms were reported after PFO closure. ${ }^{23,24}$ Furthermore, favoring the notion that OSA may allow reestablishment of an interatrial communication, treatment of OSA with continuous positive airway pressure (CPAP) has been reported to suppress a previously existing shunt occurring through a PFO. ${ }^{38}$ It is conceivable that the higher prevalence of right-to-left shunting via a patent foramen ovale in patients with OSA may be responsible for a higher stroke incidence in patients with OSA. ${ }^{39}$ Hence, the importance of an association between PFO and OSA is not to be underestimated. Given the substantial and rising number of patients with OSA, the inves- 
tigation of the following aspects should be among the priorities in studying this patient population: First, it would be very important to prospectively establish whether individuals with OSA and PFO are more likely to experience strokes and, perhaps, are more likely to suffer from pulmonary or systemic hypertension than those with OSA and absent interatrial communication. Second, given the demonstrated procedural safety, ${ }^{40}$ the impact of percutaneous PFO closure on the incidence of strokes and other undesired associated conditions such as pulmonary hypertension and systemic hypertension in this patient population should be investigated. Though it would allow further elucidation of the physiology and association of OSA and PFO, a randomized comparison of patients with OSA and PFO treated with CPAP compared to no treatment is, of course, unethical.

\section{Limitations}

As described in the introduction, TCD cannot distinguish between a shunt occurring through a PFO and a shunt on a pulmonary level. ${ }^{41}$ Albeit the latter is rare, ${ }^{42}$ its role in the pathophysiology of OSA is unknown. Likewise, a PFO causing exclusively left-to-right shunting may remain silent on TCD imaging. The clinical significance of this possibility is unclear. In addition, optimally, the prevalence of RLS in patients with OSA should be compared to that of a general population using the same imaging modality to minimize errors related to the imaging procedure itself.

\section{CONCLUSION}

The prevalence of a RLS assessed by TCD is high in patients with OSA. Provided no unrecognized other unusual intracardiac or intrapulmonary shunts are present in OSA patients, this is likely related to a high prevalence of PFO in this population. To confirm our findings, further studies comparing the prevalence of a RLS in OSA patients to that of a healthy population are warranted. It remains to be investigated whether PFO are risk factors for OSA or, to the contrary, if OSA helps maintain a PFO or leads to re-opening of a formerly closed foramen ovale. Lastly, further research is needed to determine whether PFO exacerbate the symptoms of sleep apnea or may be associated with a higher incidence of strokes in patients with OSA and, therefore, if a PFO closure should be considered in these patients.

\section{REFERENCES}

1. Hagen PT, Scholz DG, Edwards WD. Incidence and size of patent foramen ovale during the first 10 decades of life: an autopsy study of 965 normal hearts. Mayo Clin Proc 1984;59:17-20.

2. Penther P. Patent foramen ovale: an anatomical study. Apropos of 500 consecutive autopsies. Arch Mal Coeur Vaiss 1994;87:15-21.

3. Schneider B, Zienkiewicz T, Jansen V, Hofmann T, Noltenius H, Meinertz T. Diagnosis of patent foramen ovale by transesophageal echocardiography and correlation with autopsie findings. Am J Cardiol 1996;77:1202-9.

4. Meissner I, Whisnant JP, Khandheria BK, et al. Prevalence of potential risk factors for stroke assessed by transesophageal echocardiography and carotid ultrasonography: the SPARC study. Stroke Prevention: Assessment of Risk in a Community. Mayo Clin Proc 1999;74:862-9.

5. Della Volta G, Guindani M, Zavarise P, Griffini S, Pezzini A, Padovani A. Prevalence of patent foramen ovale in a large series of patients with migraine with aura, migraine without aura and cluster headache, and relationship with clinical phenotype. J Headache Pain 2005;6:328-30.
6. Morelli N, Gori S, Cafforio G, et al. Prevalence of right-to-left shunt in patients with cluster headache. J Headache Pain 2005;6:244-6.

7. Lechat $P$, Mas JL, Lascault $G$, et al. Prevalence of patent foramen ovale in patients with stroke. N Eng J Med 1988;318:1148-52.

8. Horton SC, Bunch TJ. Patent foramen ovale and stroke. Mayo Clin Proc 2004:79:79-88.

9. Schwerzmann M, Seiler C, Lipp E, et al. Relation between directly detected patent foramen ovale and ischemic brain lesions in sport divers. Ann Intern Med 2001:134:21-4.

10. Droste DW, Schmidt-Rimpler C, Wichter T, et al. Right-to-left-shunts detected by transesophageal echocardiography and transcranial Doppler sonography. Cerebrovasc Dis 2004;17:191-6.

11. Van $\mathrm{H}$, Poommipanit P, Shalaby M, Gevorgyan R, Tseng CH, Tobis J. Sensitivity of transcranial Doppler versus intracardiac echocardiography in the detection of right-to-left shunt. JACC Cardiovasc Imaging 2010;3:343-8.

12. Souteyrand G, Motreff $P$, Lusson JR, et al. Comparison of transthoracic echocardiography using second harmonic imaging, transcranial Doppler and transesophageal echocardiography for the detection of patent foramen ovale in stroke patients. Eur J Echocardiography 2006;7:147-54.

13. Horner S, Ni XS, Weihs W, et al. Simultaneous bilateral contrast transcranial doppler monitoring in patients with intracardiac and intrapulmonary shunts. $J$ Neurol Sci 1997;150:49-57.

14. Jesurum JT, Fuller CJ, Moehring MA, Renz J, Harley M, Spencer MP. Unilateral versus bilateral middle cerebral artery detection of right-to-left shunt by power M-mode transcranial Doppler. J Neuroimaging 2009;19:235-41.

15. Young T, Palta M,Dempsey J, Skatrud J, Weber S, Badr S. The occurence of sleep-disordered breathing among middle-aged adults. N Engl J Med 1993;328:1230-5

16. Bixler E, Vgontzas A, Ten Have T, Tyson K, Kales A. Effects of age on sleep apnea in men. Am J Respir Crit Care Med 1998;157:144-8.

17. Bixler EO, Vgontzas AN, Lin HM et al. Prevalence of sleep-disordered breathing in women. Am J Respir Crit Care Med 2001;163:608-13.

18. Ferguson KA, Fleetham JA. Sleep-related breathing disorders: consequences of sleep disordered breathing. Thorax 1995;50:998-1004.

19. Dempsey JA. Sleep apnea causes daytime hypertension. J Clin Invest 1997;99:1-2.

20. Guidry UC, Mendes LA, Evans JC, et al. Echocardiographic features of the right heart in sleep-disordered breathing: the Framingham Heart Study. Am J Respir Crit Care Med 2001;164:933-8.

21. Pierobon A, Giardini A, Fanfulla F, Callegari S, Majani G. A multidimensional assessment of obese patients with obstructive sleep apnea syndrom (OSAS): A study of psychological, neuropsychological and clinical relationships in a disabling multifaceted disease. Sleep Med 2008;8:882-926.

22. Gottlieb DJ, Whitney CW, Bonekat WH, et al. Relation of sleepiness to respiratory disturbance index: the Sleep Heart Health Study. Am J Respir Crit Care Med 1999;159:502-7.

23. Silver B, Greenbaum A, McCarthy S. Improvement in sleep apnea associated with closure of a patent foramen ovale. J Clin Sleep Med 2007;3:295-6.

24. Agnoletti G, Iserin L, Lafont A, Sidi D, Desnos M. Obstructive sleep apnoea and patent foramen ovale: successful treatment of symptoms by percoutaneous foramen ovale closure. J Interven Cardiol 2005;18:393-5.

25. Schaefer $\mathrm{H}$, Hasper E, Ewig S, et al. Pulmonary haemodynamics in obstructive sleep apnoea: time course and associated factors. Eur Respir J 1998;12:679-84.

26. Beelke M, Angeli S, Del Sette M, et al. Obstructive sleep apnea can be provocative for right-to-left shunting through a patent foramen ovale. Sleep 2002;25:21-7.

27. Shanoudy H, Soliman A, Raggi P, Liu JW, Russell DC, Jarmukli NF. Prevalence of patent foramen ovale and its contribution to hypoxemia in patients with obstructive sleep apnea. Chest 1998;113:91-6.

28. Beelke M, Angeli S, Del Sette M, et al. Prevalence of patent foramen ovale in subjects with obstructive sleep apnea: a transcranialdoppler ultrasound study. Sleep Med 2003;4:219-23.

29. Spencer MP, Moehring MA, Jesurum J, Gray WA, Olsen JV, Reisman M. Power $\mathrm{m}$-mode transranial Doppler for diagnosis of patent foramen ovale and as assessing transcatheter closure. J Neuroimaging 2004;14:342-9.

30. Somers VK, White DP, Amin R, et al. Sleep apnea and cardiovascular disease: an American Heart Association/American College of Cardiology Foundation scientific statement from the American Heart Association Council for High Blood Pressure Research Professional Education Committee, Council on Clinical Cardiology, Stroke Council, and Council on Cardiovascular Nursing. Circulation 2008;118:1080-111.

31. Arias MA, García-Río F, Alonso-Fernández A, Martínez I, Villamor J. Pulmonary hypertension in obstructive sleep apnoea: effects of continuous positive airway pressure: a randomized, controlled cross-over study. Eur Heart J 2006;27:1106-13. 
32. Sanner BM, Doberauer C, Konermann M, Sturm A, Zidek W. Pulmonary hypertension in patients with obstructive sleep apnea syndrome. Arch Intern Med 1997;157:2483-7.

33. Voelkel NF. Mechanisms of hypoxic pulmonary vasoconstriction. Am Rev Respir Dis 1986;133:1186-95.

34. Nootens MT, Berarducci LA, Kaufmann E, Devries S, Rich S. The prevalence and significance of a patent foramen ovale in pulmonary hypertension. Chest 1993;104:1673-5

35. Soliman A, Shanoudy H, Liu J, Russell DC, Jarmukli NF. Increased prevalence of patent foramen ovale in patients with severe chronic obstructive pulmonary disease. J Am Soc Echocardiogr 1999;12:99-105.

36. Johansson MC, Eriksson P, Peker Y, Hedner J, Rastam L, Lindblad H.The influence of patent foramen ovale on oxygen desaturation in obstructive sleep apnea. Eur Respir J 2007;29:149-55.

37. Telman G, Yalonetsky S, Kouperberg E, Sprecher E, Lorber A, Yarnitsky D. Size of PFO and amount of microembolic signals in patients with ischaemic stroke or TIA. Eur J Neurol 2008;15:969-72.

38. C Pinet, J Orehek. CPAP suppression of awake right-to-left shunting through patent foramen ovale in a patient with obstructive sleep apnoea. Thorax 2005;60:880-1.

39. Yaggi HK, Concato J, Kernan WN, Lichtman JH, Brass LM, Mohsenin V. Obstructive sleep apnea as a risk factor for stroke and death. $N$ Engl J Med 2005;353:2034-41.

40. Hein R, Büscheck F, Fischer E, et al. Atrial and ventricular septal defects can safely be closed by percutaneous intervention. J Interven Cardiol 2005;18:515-22.

41. Renz J, Jesurum JT, Fuller CJ, Reisman M, Spencer MP. Diagnosis of secondary source of right-to-left shunt with balloon occlusion of patent foramen ovale and power M-mode transcranial Doppler. Stroke 2007;38:489.
42. Khurshid I, Downie GH. Pulmonary arteriovenous malformation. Postgrad Med J 2002;78:191-7.

\section{SUBMISSION \& CORRESPONDENCE INFORMATION}

Submitted for publication August, 2011

Submitted in final revised form December, 2011

Accepted for publication January, 2012

Address correspondence to: Prof. Dr. Horst Sievert, CardioVascular Center Frankfurt, Seckbacher Landstrasse 65, 60389 Frankfurt, Germany; Tel: +49-69-4603-1344; Fax: +49-69-4603-1343; E-mal: info@CVCFrankfurt.de

\section{DISCLOSURE STATEMENT}

This was not an industry supported study. Prof. Sievert reports having study honorary, travel expenses and consulting fees from Access Closure, AGA, Angiomed, Ardian, Arstasis, Atritech, Atrium, Avinger, Bard, Boston Scientific, Bridgepoint, CardioK inetix, CardioMEMS, Coherex, Contego, CSI, EndoCross, EndoTex, Epitek, Evalve, ev3, FlowCardia, Gore, Guidant, Lumen Biomedical, HLT, Kensey Nash, Kyoto Medical, Lifetech, Lutonix, Medinol, Medtronic, NDC, NMT, OAS, Occlutech, Osprey, Ovalis, Pathway, PendraCare, Percardia, PFM Medical, Recor, Rox Medical, Sadra, Sorin, Spectranetics, SquareOne, Trireme, Trivascular, Viacor, Velocimed, and Veryanand. He also holds stock options in Cardiokinetix, Access Closure, Velocimed, CoAptus, Lumen Biomedical, Coherex. The other authors have indicated no financial conflicts of interest. 